\title{
CHANGES IN CARBOHYDRATE MARKETING AS AFFECTED BY RESEARCH
}

\author{
Arthur G. Holstein \\ Pfanstiehl Laboratories, Inc. 1219 Glen Rock Avenue, \\ Waukegan, Illinois 60085, USA
}

\begin{abstract}
Changes in carbohydrate marketing resulting from research began with the advent of industrial sugar production and has since been greatly influenced by purc, applied and analytical research.

Progress in sugar technology was reflected in the early imposition of an excise tax on sugar and by the continued upward revisions of the tax.

As dextrose evolved into a commodity it acquired a prominent position not only as a food but as an intermediate for producing many chemicals of commercial significance; frequently by using scientific knowledge that had come to light through carbohydrate research during the previous century. As sugar production became more sophisticated the need for exchange of technical information was recognized by chemists and culminated in the establishment of the Division of Sugar Chemistry and Technology in 1920. As the interest in sugars developed, the name of the Division was changed in 1949 to the Division of Sugar Chemistry and in 1951 to the Division of Carbohydrate Chemistry.

The appearance of newer instrumentation and techniques subsequent to World War II made it possible for scientists to probe more deeply into molccular structure and its biological implications. The findings interested workers in other disciplines and new scientific abilities were encouraged to look toward carbohydrate chemistry and technology. This interest brought the need for many new carbohydrates and their derivatives to be made commercially.

Pfanstichl Laboratories is the result of a government effort during World War I to develop a domestic source of biological chemicals. In this particular instance rare sugars were initially required for use in the identification of microorganisms, especially those producing human ailments. Since then Pfanstiehl, with the hclp of its many scientific friends, has endeavoured to keep abreast of research and industrial needs.
\end{abstract}

The marketing of carbohydrates has always been influenced by research. As time has passed the research became more imminent and its effect more powerful. This interaction has continued until today research immediately and directly strongly affects marketing. What is more, marketing is affecting research by its indication of useful problems whose solution will benefit humanity and will bring financial reward to both research and marketing.

W. D. Horne in 1915 aptly expressed the relation of marketing and research in an article ${ }^{1}$ entitled Contribution of the Chemist to the Sugar Industry published in the Journal of Industrial and Engineering Chemistry. He said, 
'Chemistry as a science has contributed so much toward the development of the sugar industry from the beginning that the association has been a continuous one and cannot be looked upon as having been abruptly formed at any particular time, but rather as having been the principal factor in the development of sugar manufacture'.

He further said,

Thus the influence this science has exerted upon the industry during the past quarter century should be viewed in relation to what has preceded and what will follow. Much of what chemistry is doing now is the development of earlier work and will continue to exert its influcnce upon the future. Every department of the industry has long been under searching chemical investigation in almost every detail. Agriculture, manufacture, refining and utilization in the arts have called for chemical assistance and have received noteworthy aid. Very many new processes have been developed, better methods of analysis have been devised and theoretical knowledge of the constitution of the sugars has been substantially advanced.

Cane sugar as a sweetening agent was used first in the South Pacific Islands. The natives of the islands did not process the sugar cane for the sugar, but used the stocks as a source of food because of their sweet tast $\mathrm{c}^{2}$. The first manufacture of sugar, that is sucrose, from sugar cane occurred in India no later than 400 B.C., and perhaps earlicr. The art of growing sugar cane and recovering sugar from it spread slowly, first through Persia, Asia Minor. Egypt, North Africa, Sicily, Spain and Madeira and ultimately, shortly after the discovery of America, to the Caribbean Islands. It is said that sugar was brought to America by Columbus from the Canary Islands on his second voyage.

The importance of cane sugar as a commodity was early recognized in the United States and the newly formed government soon placed an excise tax on its importation. The tax resulted from the Act of July 4. 1789. It is interesting to note that as the sugar industry progressed and refinements were made, the excise tax was continually revised upward.

The first act covered all sugars. In 1794 an additional tax was applied to clayed or lump sugar. In 1795 the duties on clayed sugars were increased $1 \frac{1}{2}$ cents per pound. White powdered sugars were assessed 3 cents a pound. In 1812 Derosne developed bone black, in 1824 Howard invented the vacuum pan and in 1829 Rillieux, the multi-effect evaporator. These improvements in processing were also reflected in further increases in tax revenue. The first distinction between raw and refined sugars was made in 1842 and on August 5 , 1861, sugars were evaluated on the basis of the Dutch Standard Colour Test. In the latter part of the 19 th century and the early part of the 20th century, great advances were made in the cane sugar industry and the manufacture of raw sugar was brought under chemical control.

The consumption of sugar in the United States increased from $1{ }_{2}^{1}$ million tons in 1890 to $2 \frac{3}{4}$ million tons in 1914 with an increase in per capita consumption from 54 pounds to 84 pounds per annum, and by 1968 had increased to $10 \frac{1}{4}$ million tons, or 101.9 pounds per capita ${ }^{1.3,4}$.

It was shortly after 1914 that D-glucose, commercially referred to as 'dextrose' became a recognized commodity. Glucose is the central metabolic 
Table 1. Sugar, raw and refined: rate of duty per pound

Act of July 4,1789

On brown sugar

On loaf sugars

On all other sugars

Act of June 7, 1794

After June 30 on clayed or lump sugar shipped to the United States:

In United States vessels, an additional rate of

In foreign vessels, an additional rate of

Act of January 29,1795

'That after the said last day of March next, the present duties payable upon clayed sugars, shall cease and there shall be paid upon all white clayed or white powdered sugars, three cents per pound, and upon all other clayed or powdered sugars, one-and-one-half cents per pound.'

Act of August 30, 1842

Raw sugar and on brown clayed sugar

On all other sugars not refined

Refined sugar, including tinctured, colored, or otherwise adulterated

Act of August 5. 1861

(Dutch standard of color test adopted)

Sugars not above No. 12 Dutch standard of color

Sugars above No. 12 Dutch standard of color

sugar of nature and, hence, is of wide occurrence both free and combined. It is principally found combined in polysaccharides and one of these, starch, is the industrial source of dextrose.

Shortly after the turn of the 18th century, Kirchoff discovered glucose in starch hydrolyzate and eventually obtained the sugar in crystalline form. It was not until several years later that the French chemist, Saussure, gave a scientific explanation for the conversion of starch to sugar. This sugar, identical to the sugar found in grapes and other sweet fruits, was named 'glucose' from the Greek word glukus meaning sweet ${ }^{5}$. The importance of Kirchoff's discovery was fully recognized in 1812 when he was awarded a yearly pension of 500 roubles for life and decorated with the Order of St. Ann, Second Class, by the Russian empire.

When Napoleon Bonaparte placed an embargo on colonial products with the object of destroying English trade in continental Europe, it became necessary to establish in French and German factories the production of glucose which took the place of cane sugar. The price of glucose, made from starch, was rather high. The products were sold either as a syrup or as a solid. The latter was obtained by allowing magma from a high purity syrup to crystallize. Since glucose was manufactured chiefly from potato starch, it was sold as potato sugar or potato syrup.

In the United States manufacture of syrups and sugars from starch can be traced back to 1830 when a patent was granted to Amable Brozier of 
Philadelphia. This patent was for saccharification of maize, rice and other grains. During the early era of the industry, commercial sugars were not pure. They were mainly solidified sugar solutions or magmas containing dissolved mineral matter, dextrin and other impurities.

In 1911 E. G. Porst of Corn Products Refining Company initiated a detailed investigation to develop manufacturing techniques for dextrose. The research made it possible for him to produce a white anhydrous dextrose of almost 100 per cent purity. This sugar was made available to other laboratories and hospitals.

In 1915 Porst visited the sugar laboratories of the Bureau of Standards and collaborated with F. J. Bates and Dr. R. F. Jackson. Bates was responsible for designing the widely used saccharimeter which carried his name. The work of the Bureau's laboratorics was largely responsible for improvements leading to the production of high purity dextrose. During this period the Danish sugar chemist, C. C. Winther, assisted Corn Products Refining in installing crystallizing, centrifugal and drying equipment which permitted them to produce pure dextrose of white colour.

In June 1919, through the courtesy of the Bureau of Standards, W. B. Newkirk, an associate chemist of the Sugar Laboratories, visited the Corn Products Laboratories. With his assistance it was possible to produce commercial white dextrose of 99 per cent purity from dark syrups. In 1920 , Dr. Newkirk became associated with Corn Products Refining Company and assisted in the establishment of a plant capable of producing dextrose on a large commercial scale.

In considering these industrial advances which have marked activities in the carbohydrate field, it is important to note that some would not have occurred had it not been for the useful knowledge derived from academic researches. Universities and government laboratories have assisted greatly in providing the fundamental knowledge necessary for a progressive carbohydrate industry.

During the 19 th century much scientific literature was published covering research on sugars other than glucose and sucrose. These investigations were greatly stimulated by the fabulous work of Emil Fischer beginning with his use of phenylhydrazine as a reagent. The impact of his remarkable work, including his establishment of the configuration of D-glucose, as well as comparable developments in the 20th century in England was not fully felt in the United States until the period immediately following World War I.

Uronic acids had been isolated from gums, D-glucosamine obtained from lobster shells and D-galactosamine from chondroitin. Chemical reactions such as the reduction of sugars to alcohols using sodium-mercury amalgam, the Ruff's degradation for conversion of D-gluconate to D-arabinose, the Kiliani reaction and the oxidation of sugars to their sugar acids using electrolytic oxidation with bromine were all studied. This was research of the purest form. Such research did not have an immediate impact on the market-place.

Subsequent events placed increased emphasis on industrial research and academic research began to provide ever increasingly useful information.

In 1919 C. A. Browne, W. D. Horne, H. Bryan, F. J. Bates and F. G. Wiechmann began discussions and correspondence with other sugar 
chemists about establishing an organization to cover the field of sugar chemistry and technology. Since all were members of the American Chemical Society, an association under the auspices of the Society was thought to be advantageous. A plan for incorporating this proposal was published in 1919 in the magazine, Facts about Sugar, and the first session of the newly formed Division of Sugar Chemistry and Technology was held in St. Louis on April $14,1920^{6}$.

As glucose became commercially available, producers began to evaluate the sugar not only as a product for the food industry, but also as a chemical intermediate. Glucose was used as a source of sorbitol and then sorbitol became an intermediate for sorbose, itself an intermediate in the synthesis of ascorbic acid.

Glucose today is oxidized both enzymatically and chemically to produce gluconic acid. Gluconic acid is used widely for chemical leavening in the baking field. Its salts are used in the pharmaceutical industry. Sodium gluconate and sodium glucoheptonate, which is produced from glucose by the Kiliani reaction, are both used as ligands to form water-soluble chelates in the conditioning of water. These ligands are also used for alkaline derusting, descaling of metal, for paint stripping, and as inhibitors against the caking of aluminum oxide on heating coils in aluminum etching tanks,

Both sodium gluconate and sodium glucoheptonate are used to retard setting of cement and as scavengers for trace metal contaminants in finishing of textiles and to prevent over-oxidation, or tenderizing of fabric with the formation of pin holes in cloth. Their presence prevents lakc formations in dye baths.

Sodium $\alpha$-D-glucoheptonate is used as a source of $\alpha$-D-glucoheptono- $\gamma$ lactone. This lactone is used to esterify antibiotics to provide stability. Antibiotics are sensitive to highly acidic environment. The $\gamma$-lactone is ideally suited for use as a mild esterifying agent because its equilibria in aqueous solution maintains a very mild acid $\mathrm{pH}$. Glucoheptono- $\gamma$-lactone, even though mildly acidic, has the power to solubilize calcium and sodium mucates on teeth and yet not be harmful to the tissues of the mouth. Hence, it is now being used as a denture cleaner in hospitals because its lack of toxicity makes it a safe product for bedside use. It is now being more widely evaluated in oral hygiene as a mouth wash or component of dentifrice.

The calcium salt of $\alpha-D$-glucoheptonic acid today is the preferred calcium salt used by the government for preparation of parenteral solutions. The reason it is preferred is that it is a non-crystallizable salt which insures stability of the prepared solutions, which calcium gluconate does not do. Though both are safe, calcium glucoheptonate has an even lower toxicity than calcium gluconate.

Another product of glucose that is important today is methyl $\alpha$-D-glucoside. This is used in the manufacture of polyethers, esters and other products associated with polyols which are used in rigid urethane foams, modified urethane coatings and in industrial emulsifiers and surfactants. Glucose has been used also in fermentation to produce lactic acid.

The demand for glucose as a chemical intermediate has grown until 13.4 per cent of the glucose produced goes into chemical applications. In 1968, 
154 million pounds of glucose was used by the pharmaceutical and chemical industries?

Sucrose has not become as important a chemical intermediate as glucose. However it is used as a starting raw material in the commercial production of mannitol. It is also a source of fructose which is produced commercially by the fermentation of invert sugar using Aspergillus niger. The glucose is oxidized to the gluconate which is readily removed leaving the fructose. The fructose is then removed from the mother liquor by forced crystallization ${ }^{8}$.

Measurement of carbohydrate quality, as for all chemicals, has been limited by the tools available. Prior to World War II identity of a biochemical compound was based on such analysis as elemental composition, specific rotation, index of refraction, preparation of derivatives and biological activity. Purity was determined by such tests as specific rotation, melting points and colour reactions. Sometimes analysis included residue on ignition, chlorides, sulphates, heavy metals, arsenic and measurement of other impurities that might be present from the raw material source.

Research laboratories have been responsible for developing new instrumentation and new methods to assay quality and molecular structure. Simple tests, such as paper chromatography, have often brought to light the presence of contaminants that heretofore had not been detected. New values can now be determined by electrophoresis, spectrophotometry and u.v. absorption while other contaminants or products can be identified by gas-liquid chromatography and atomic absorption. Products are now rapidly fingerprinted by use of infrared and n.m.r. With these tools available, research laboratories today are able to probe into the make-up of nature, and have begun to understand in accurate detail the various components that make up molecules.

This investigative work has been particularly important in biological chemistry. It is significant and important to identify the active components in a particular molecule. It is interesting to note that very often biological activity is related to carbohydrate components of active molecules. For example, some time ago Seymour Cohen became interested in the nucleosides, known as spongouridine and spongothymidine isolated by Werner Bergmann from a sponge, Crytotethya crypta. These nucleosides are 1- $\beta$-Darabinofuranosyl derivatives of uracil and thymine. The work initiated a study of the environment of the sponge and the biosynthesis of the arabinofuranosyl nucleosides. It further stimulated interest in the relationship of the D-arabinosyl moiety to the D-ribosyl and 2-deoxy-D-ribosyl residues of nucleosides 9 .

In the years following a great interest developed in nucleosides and in the preparation of analogues to support various biological investigations and those directed toward anti-tumor nucleosides.

These investigations required particular sugars and procedures for making nucleosides. The large quantities needed made it necessary that the sugars and nucleosides be made commercially. In addition, there was need for unnatural nucleosides, such as 9- $\beta$-D-arabinofuranosyl adenine, 9- $\beta$-Darabinofuranosyl cytosine, 5-aza-cytidine and 6-mercapto purine arabinoside. These have been in particular demand for cancer chemotherapy.

Laboratories doing carbohydrate and biochemical research needed and 

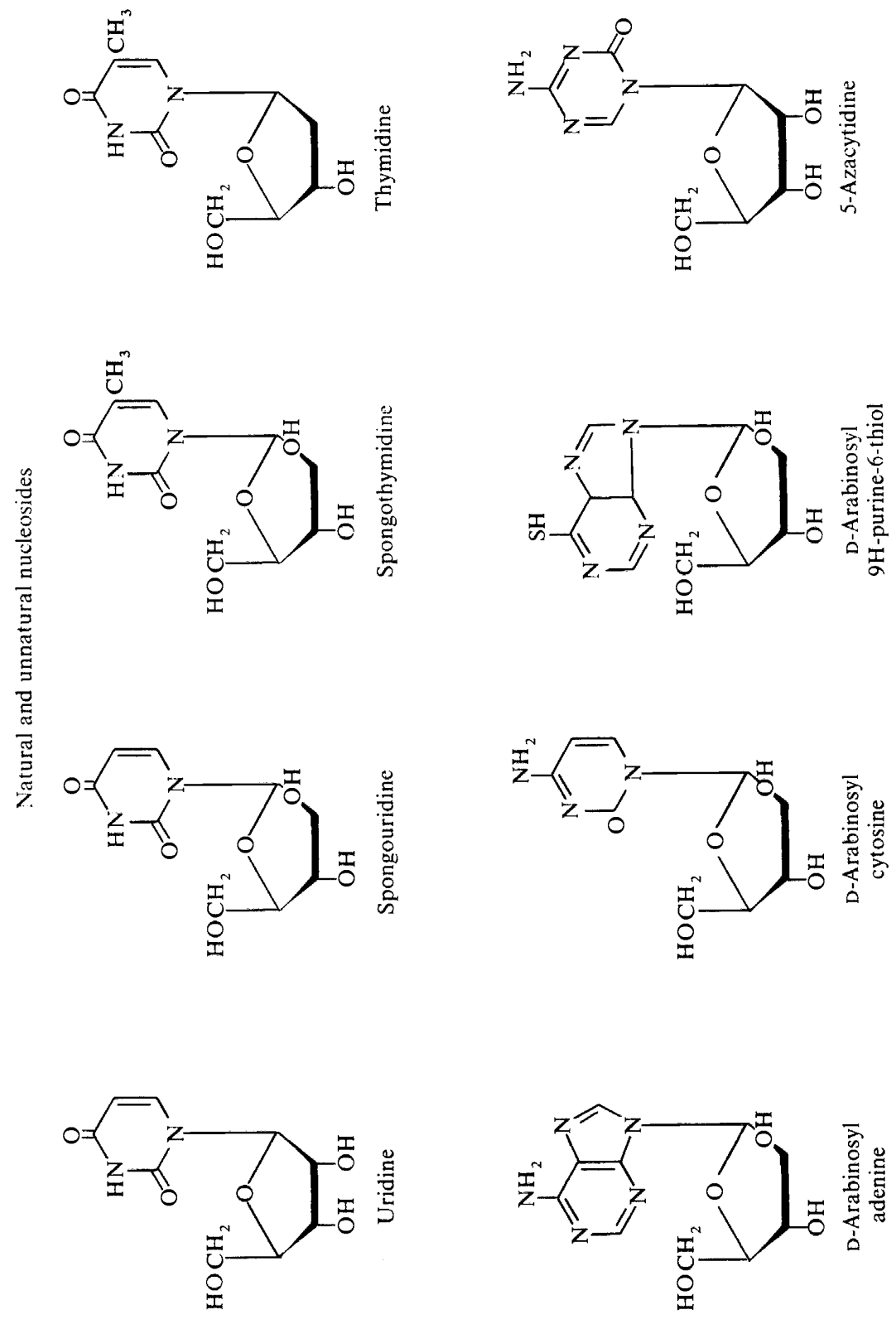
requested commercial laboratories to prepare the gamut of carbohydrates and derivatives. Today commerciail laboratories not only offer pentoses, hexoses, disaccharides and trisaccharides, but also amino sugars, deoxy sugars, acetylated, benzylated and isopropylidene blocked sugars, sugar alcohols and radioactive sugars.

Some natural sugars not previously requested, such as mannoheptulose, from the avocado, are available for study and treatment of hypoglycemia. The $\mathrm{N}$-acetyl derivatives of muramic acid, neuraminic acid, glucosamine, mannosamine and galactosamine are also now available commercially. There have been demands recently for a branched chain sugar. Hence, apiose is isolated from eel grass and offered as the crystalline isopropylidene derivative. Because of repeated demands 5-deoxy-L-arabinose is prepared from L-rhamnose. This sugar is an important intermediate in the preparation of Biopterin. Stachyose, which is isolated from the Japanese artichoke, has been required as a reference for evaluating food for NASA. L-Lyxose has been required by research laboratories for nucleoside synthesis. L-Lyxose is prepared commercially from D-galacturonic acid which is isolated from pectin.
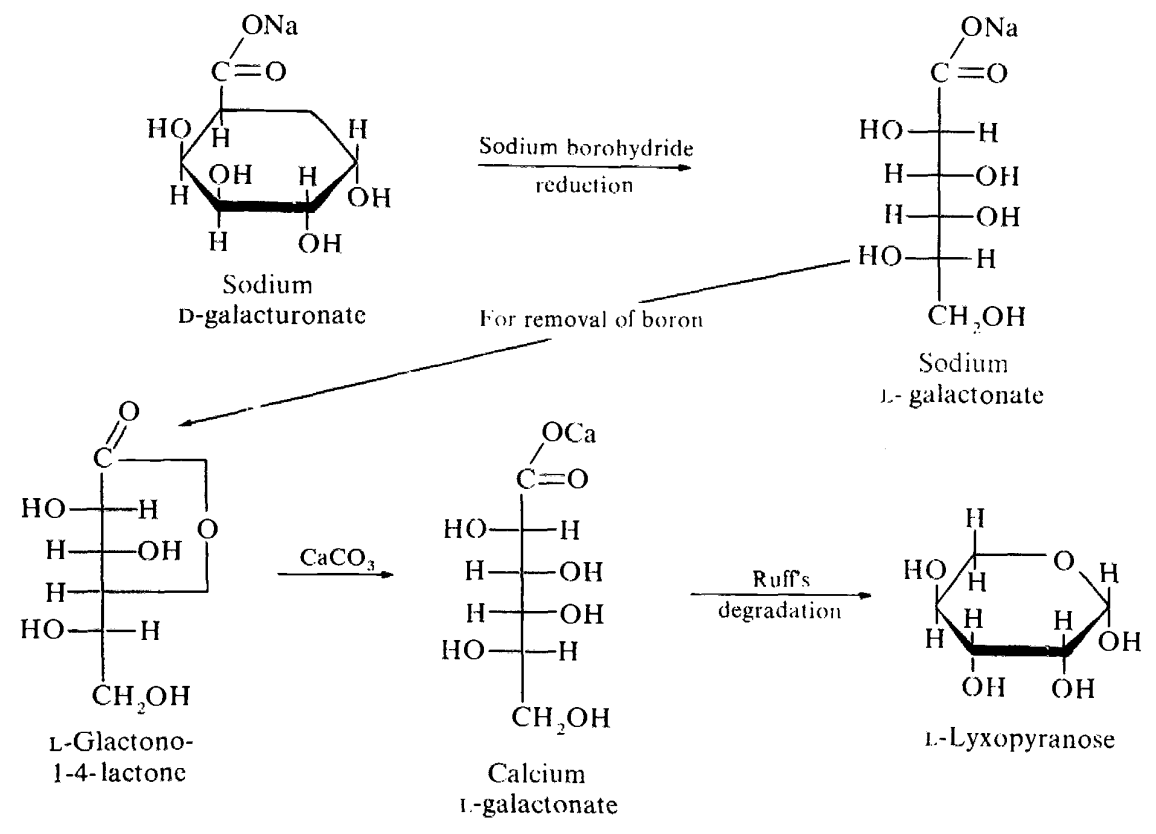

The sodium salt is reduced with sodium borohydride to the sodium Lgalactonate which is then converted and isolated as L-galactonolactone. This is then converted to L-lyxose by means of the Ruff's degradation.

Some of the lesser known sugars, such as L-arabinose, are now used in commercial quantities. L-Arabinose has a peculiar property that causes it to react with amino acids in a Browning type of reaction to produce artificial flavouring simulating chicken and beef. Such flavours are important in 
animal feed, in the preparation of palatable low cost protein foods. Other sugars are important as nutrient media in the production of serum and antibiotics while others are useful as diagnostic tools. Glucosamine hydrochloride is used as an extender for antibiotics.

Recently xylose has become important as a nutrient media for the production of the enzyme isomerase which is used for the partial conversion of glucose to fructose. This enzymatic conversion of glucose to fructose may have a tremendous impact in the sugar market. Those who are familiar with dextrose and sucrose markets recognize that until the latter part of 1971 commercial dextrose was always sold at 79 per cent of the price of sucrose. Much of the sucrose sold is offered as a liquid sugar (invert) to the commercial food field. One can appreciate that if dextrose sells at 79 per cent of the price of sucrose, or 79 per cent of the price of invert sugar, it is very attractive economically.

The laboratories producing the lesser known carbohydrates have found servicing this industrial and research market most challenging. The obvious natural source from which a certain sugar had been isolated was frequently not the obvious source when it became necessary to obtain adequate raw material to meet the needs of the market.

Many years ago our laboratories relied on a button factory for a source of ivory nut scrap from which $\mathrm{D}$-mannose could be readily produced. The whole ivory nut was too difficult to work with. Progress took its toll, plastic buttons destroyed the market for ivory nut buttons. Fortunately, shortly after this episode ivory nut flour became available as a polish used in tumbling barrels for cleaning metals. Prior to World War II salicin was produced from willow bark, a by-product of the basket industry in England. This industry disappeared with the war. Since then salicin has been in short supply. Today we are evaluating various sources of this glycoside to find one that will yield an economically competititive glycoside which now is becoming important as a diagnostic tool.

As previously mentioned, the demand for L-arabinose has expanded because of its unique capability to complex with protein to simulate meat flavouring. When demand expanded we were soon to offer bulk L-arabinose because of our production experience in obtaining it from mesquite gum. We placed money in escrow for the gathering of mesquite gum. Unfortunately, when the harvest season arrived there was no crop. The rains had washed the gum into the ground. The next year the weather was not suitable for gum exudation. Hence, our laboratories were forced to use gum ghatti, a commercial gum as a source of L-arabinose. Gum ghatti is more expensive, requires a different type of processing, is very difficult to work with, yields less sugar and made the L-arabinose market economically unattractive for the two years during which mesquite gum was unavailable.

Rhamnose is now in extremely short supply. European sources no longer exist. Years ago our laboratories used lemon flavine as a rhamnose source. This is no longer available. Today we are producing rhamnose from naringen. This is not only extremely expensive, but it, too, is in very short supply and hence it is difficult to meet the needs of the biochemical market.

Sometimes sugars are available in natural sources requiring difficult and expensive processing. The sugars are consequently expensive. Some of these 
sugars are now produced synthetically at a cost that is much less than would be the cost of isolation from natural sources. This situation applies to sugars such as $N$-acetyl-D-mannosamine which is readily produced by epimerization of $N$-acetyl-D-glucosamine. Years ago D-galactosamine was isolated from chondroitin by the classical procedure: today we start with D-galactose and oxidize it to the galactonate.

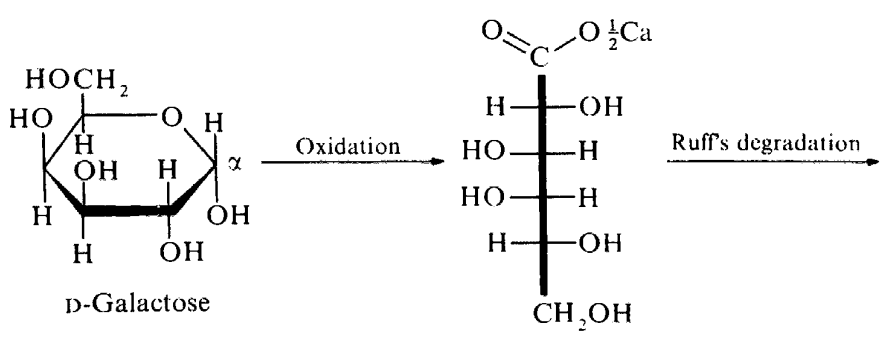

Ca Galactonate

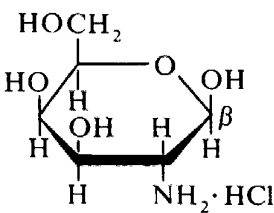

D-Galactosamine $\cdot \mathrm{HCl}$

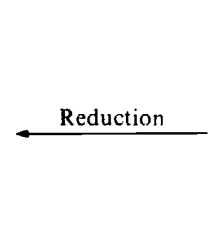

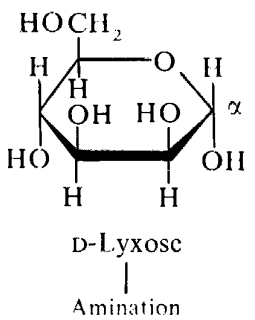

Kiliani

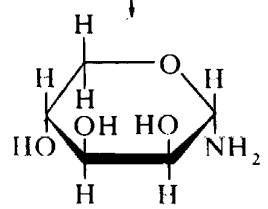

D-Lyxosylamine

Galactosaminic acid nitrile

We then do a Ruff's degradation and isolate-D lyxose which we then convert to lyxosylamine. This is followed by a modified Kiliani reaction to form the acid nitrile which is catalytically reduced to the end product, D-galactosamine hydrochloride.

Despite all of these steps we are able to offer a product whose purity far exceeded any isolated from natural material and which is much less expensive.

The interplay between producers of carbohydrates and the customers is extremely helpful to both. The lines of communication are telling the producer what is needed and often how to do it. The producer on the other hand is making available the compounds for research and biological work and often guides the customers as far as possible.

At one time the government was interested in trisaccharides as a possible stabilizer for whole blood. They wished us to contract for a substantial quantity of melezitose. Although our laboratories at the time had an immense inventory of the sugar and melezitose honey, we told them they should try raffinose. The latter was continuously available, but melezitose is not. When our supply of melezitose would be exhausted we might not get more. Melezitose comes from a unique and scarce melezitose honey that is obtained only after unusual and rare weather conditions. Hence if our supply became 
exhausted and we could not get more melezitose honey we would not want a large user to be dependent on it.

It is interesting to note that as technical interest spread beyond sucrose, interest in carbohydrate chemistry also spread to the chemistry of other sugars. The name of the Division of Sugar Chemistry and Technology of the American Chemical Society was changed in 1949 to The Division of Sugar Chemistry and finally in 1951 to The Division of Carbohydrate Chemistry.

Prior to World War I, 90 per cent of the medical and biological chemicals used in the United States were imported from Germany. During the early period of the war the United States dependence on imports was recognized. Consequently the government took steps to rectify this deficiency by encouraging domestic drug and chemical companies to produce new drugs and biologicals.

At this time the government approached Professor Stieglitz of the University of Chicago to enquire the location of laboratories which could produce some of the required biological chemicals. He recommended that they request Carl Pfanstiehl, a young scientist located in the Chicago area, to consider starting a laboratory for the production of needed biological chemicals. This culminated in the establishing of the Special Chemical Company by Carl Pfanstiehl in 1918. He hired a young graduate of Washington University, Mr. Robert Black. The laboratory was set up in the basement of Carl Pfanstiehl's home in Highland Park, Illinois. The first Pfanstiehl chemicals were produced in 1918. The first price list was dated May 1, 1919. It included the following: dextrose, dulcite, galactose, inulin, mannite, xylose. By November they had added: arabinose, levulose from inulin, mannose, rhamnose, sorbite, raffinose, maltose (anhydrous).

In recognition of his responsibility, Carl Pfanstiehl printed the following on the fly leaf of his catalogues.

Special Chemicals Company, devoted to the chemical independence of Amcrica. The Special Chemicals Company was organized to do its share toward making this country independent of foreign nations in its supply of laboratory chemicals, At the urgent request of the Government, we first developed a number of bacteriological sugars. Several rare laboratory chemicals of exceptional quality, to which we are constantly adding, have been produced in response to repeated requests.

He also published in his advertisement brochure a special article on bacteriological sugars and their uses. Reference was made to the Bates Half-Scope Polariscope, which was made available to Pfanstiehl Laboratories, one of four matched instruments produced in Austria by Joseph and Jon Frick for the Bureau of Standards.

In the early twenties Carl Pfanstichl changed the name of the company from Special Chemicals Company to Pfanstiehl Chemical Company. As the needs of biological and other research laboratories increased, additional sugars and derivatives were made available. Much of this development could not have occurred had it not been for the excellent scientific research published, and for the generosity, personal guidance and counsel offered by scientist friends. 
In 1955 an article appeared in the business section of the Chicago Sun Times, titled; 'Producer of Rare Sugars', with the caption, 'Weird Things Brew at Pfanstiehl'.

In the cauldron boil and bake

Liver of rabbit, and windpipe of cattle,

Honey of hemlock, and shell of lobster,

Willow's bark, and dahlia's tuber,

Ivory nuts, and artichokes--

For a charm to fight off trouble,

Like a hell-broth boil and bubble.

Quoted from a witch in 'Macbeth"?

Guess again.

These are among the many weird ingredients used by the 20th Century firm of Pfanstiehl Laboratories.

\section{REFERENCES}

1 W. D. Horne, Ind. Engng. Chem. 7, 278 (1915).

R. A. Ballinger, $A$ History of Sugar Marketing, US Dept. Agric. Ec. Report No. $197: 2$ (1971).

3 Sugar Statistics and Related Data, Vol. I (Revised), 158. US Dept. Agric. (1970).

${ }^{4}$ Sugar Statistics and Related Data, Vol. I (Revised), 14. US Dept. Agric. (1970).

5 E. G. Porst, Chemical Age, June, 213 (1921).

6 W. D. Horne, S. M. Cantor and R. W. Liggett, Ind. Engng. Chem. 43, 807 (1951).

7 E. C. Snyder, Symposium Proceedings Corn Refiners Assn. VIII-II (1970).

8 A. G. Holstein and G. C. Holsing, US Pat. 3050444 Aug. 21 (1962).

9 S. S. Cohen, Persp. Biol. Med. 6, 215 (1963). 